\title{
A Model of Recommended Retail Prices
}

\author{
Dmitry Lubensky \\ University of Michigan
}

August 19, 2011

\begin{abstract}
Manufacturers frequently use list prices, suggested retail prices, or other similar forms of non-binding public price recommendations. Despite the prevalence of this practice, why manufacturers make these recommendations and what effect they have on actual prices is still not well understood. I present a model in which price recommendations convey information to consumers about aggregate market conditions. The manufacturer uses recommendations to directly affect consumers' search decisions and thus to indirectly affect the prices set by retailers. The manufacturer faces a tradeoff when influencing search: inducing lower reservation prices reduces retailer markups but also inhibits the manufacturer's ability to extract surplus from consumers with a high willingness to pay. I show that the manufacturer can credibly provide information through cheap talk. Furthermore, I find that a ban on recommendations can be welfare reducing, harming both consumers and the manufacturer. Lastly, I argue that price recommendations are not simply a substitute for price restraints and allow the manufacturer to achieve outcomes that are not attainable with resale price maintenance alone.
\end{abstract}




\section{Introduction}

Manufacturers routinely use non-binding recommended retail prices in markets ranging from common household goods found at the grocery store to big ticket items such as electronics, appliances, and cars. These recommendations come in a variety of forms (list prices, manufacturer suggested retail prices (MSRPs), sticker prices, etc.) and are made visible to consumers whether they shop at a brick and mortar retailer or online. There is consensus that price recommendations are closely linked to real market outcomes. This relationship has both been shown empirically (e.g. Faber and Janssen (2008)) and also implicitly assumed in the myriad studies that use recommendations as a proxy for transaction prices (e.g. Berry, Levinsohn, and Pakes (1995)). There is also anecdotal evidence that recommendations can directly affect the decisions of market participants. For example, when buying a new car consumers know not to accept a price at or above MSRP and strategic dealers seem to take this into account as they set prices. ${ }^{1}$ However, despite the evidence that price recommendations effect behavior, our understanding of how they do so is quite limited. In part due to the fact that price recommendations are non-binding, the mechanism by which they have an impact and the motives of the manufacturer in making these recommendations are still not well understood.

In practice, most products tend to sell at or below their recommended price, hence a common explanation is that recommendations act as price ceilings. This story is compelling because how a manufacturer benefits from a price ceiling is well understood. Retailers with market power impose additional markups which hurt the manufacturer's sales and the manufacturer can resolve this problem with a price ceiling (Mathewson and Winter (1984)). Yet such an explanation of recommendations is incomplete. Since price recommendations are nonbinding, at least in name, it is not clear why a manufacturer would make a recommendation instead of just imposing a price ceiling directly. In addition, manufacturers often go to great lengths to publicize their recommendations through advertising or by printing them on product packaging. An explanation of recommendations as explicit price ceilings ignores the potential role played by consumers.

This paper provides an alternative explanation in which price recommendations directly affect consumers' search behavior. Rather than explicitly restraining retailers, price recommendations provide consumers with information. Consumers are uncertain about aggregate market conditions and when they engage in costly sequential price discovery, they do not know the distribution of retail prices. Consequently, when a consumer observes a particular price, she does not know if it represents a "good deal" or whether she should keep searching. With a price recommendation the manufacturer reveals this information and helps consumers decide between purchasing or continuing to search. Retailers anticipate consumers' reactions to the recommendation and adjust their prices accordingly. By this mechanism, non-binding price recommendations directed at consumers have a real impact on consumer and retailer

\footnotetext{
${ }^{1}$ While the majority of vehicles sell for prices strictly below MSRP there have been a few notable exceptions such as the Toyota Prius.
} 
behavior, and thus on market outcomes.

Price recommendations help consumers avoid the costs of learning about market conditions. But what incentive does the manufacturer have to provide this information? I show that by informing consumers and affecting search, the manufacturer faces a classic price-quantity tradeoff. In the main model consumers have either a high or a low valuation for the manufacturer's product. When a price recommendation induces consumers to reject high prices, the manufacturer restricts his ability to set a high wholesale price and cannot extract as much surplus from high valuation consumers. At the same time, when consumers reject high prices retailers are forced to reduce their markups and this increases sales to consumers with low valuations. Hence inducing more search trades off serving more low valuation consumers for extracting surplus from high valuation consumers, and which of these two effects is more important for the manufacturer depends on market conditions.

Since the manufacturer has a vested interest in how much search is undertaken, there is an issue of credibility. If the manufacturer has incentive to mislead consumers, consumers would rationally ignore recommendations and then no information can be transmitted. Furthermore, assuming this issue away by imposing an exogenous penalty for lying may be unrealistic. For example consider a book cover with one of two possible statements: "best seller" or "MSRP \$19.99". Assuming that the first statement must be truthful is reasonable since whether a book is a best seller is easily verified. But the price recommendation is not a falsifiable statement; it is not immediately obvious how a manufacturer can be accused of recommending a "false" price. In a main result, I show that credibility often does not have to be assumed and that the manufacturer can communicate market conditions to consumers using cheap talk.

The cheap talk result stems from the fact that the manufacturer's and consumers' interests can be aligned. In the main model, there is uncertainty about aggregate demand, modeled as the proportion of consumers with a high valuation. The manufacturer and retailers observe aggregate demand but consumers do not. Recalling the manufacturer's tradeoff to inducing search, he prefers less search in states when consumers are predominantly high types and more search in states when consumers are predominantly low types. For their part, consumers expect retailers to charge high prices when aggregate demand is high and low prices when aggregate demand is low and accordingly prefer to search more in the low demand state and search less in the high demand state. Since the two parties agree on whether more or less search is desirable in either state, by the logic in Crawford and Sobel (1982) the manufacturer can credibly convey information to consumers and the cheap talk result goes through.

To address how one should consider price recommendations from an antitrust perspective I present two policy experiments. First, I examine a ban on recommendations and find that in situations in which aggregate demand is sufficiently uncertain, the ban can reduce welfare and in particular the surplus of the manufacturer and consumers. I show that in equilibrium only consumers with high valuations engage in search, and the welfare result hinges on 
this observation. High valuation consumers, by virtue of having learned their type, believe it is more likely that aggregate demand is also high and hence they are on average overly pessimistic about the distribution of prices. As the amount of uncertainty about aggregate demand is increased, high demand consumers become more pessimistic and eventually no search can be supported. This results in a loss of sales to consumers with low demand due to higher downstream prices and a loss of sales to consumers with high demand that may exit the market prior to observing a price they would accept.

Given that price recommendations tend to look like price ceilings in practice, and that even in the context of the model presented here every recommendation maps to some upper bound on prices, a natural question is whether recommendations are just a substitute for price ceilings. I contend that this is actually not the case and that there is a distinction to be drawn between information and control. While a price ceiling gives the manufacturer power to directly influence retail prices, it does not allow the manufacturer to directly influence consumers' search behavior. I present an informal argument suggesting that there are outcomes that the manufacturer can achieve with recommendations that are not available with price ceilings alone.

While there is an extensive theoretical and empirical literature that deals with vertical relationships, an explicit treatment of the role of price recommendations has been largely lacking. Price recommendations have long been lumped in as an instrument of resale price maintenance with the mechanism behind them left unexplored. Recently though, the question of what impact recommended retail prices can have given that they are non-binding has been posed in two papers. Buhler and Gartner (2009) propose a repeated setting where the recommendation guides a retailer about which price to set under threat of future punishment. A different approach is taken by Puppe and Rosenkranz (2006), in which the price recommendation directly enters loss-averse consumers' utility functions as the reference point. My model provides a different mechanism from both of these papers. I depart from Buhler and Gartner by modeling recommendations as messages to consumers and in doing so argue that recommendations are more than vertical restraints. In addition, unlike Puppe and Rosenkranz, I provide an explanation where the role of recommendations is not to change consumer preferences but rather to provide information. That recommendations affect consumers' behavior is not assumed but instead emerges in equilibrium, and the effect that recommendations have is not fixed by the model but rather is determined by market conditions.

Although I focus on price recommendations in vertical markets, there is a literature on the role of non-binding list prices in markets where producers sell directly. An example is residential housing, in which studies such as Horowitz (1992) have empirically demonstrated the relationship between list and transaction prices. Still, the theoretical foundations for why this relationship should exist have been largely lacking. For instance, while Horowitz conjectures that list prices help inform consumers of a seller's reservation price, he does not show that such information can be credibly communicated in an equilibrium. By contrast, theoretical models of list prices in this setting rely on them being more than just information. 
For example, Gill and Thanassoulis (2010) explicitly characterize the effect of list prices on industry competition, but in doing so assume that list prices act as binding price ceilings. I propose a mechanism by which price communications are truly non-binding, and yet have a real impact by providing consumers with information that affects their search. While a vertical structure plays an important role in my results, this approach of modeling list prices as cheap talk can potentially help us understand their role in the housing and other related markets.

Lastly, this paper provides a modest methodological contribution to the literature on price search with aggregate uncertainty. Models in this literature either have sequential search but only two firms (Benabou and Gertner (1993)) or a larger number of firms and non-sequential search (Yang and Ye (2008)). The issue is tractability: sequential search with many firms potentially allows for equilibria where consumers follow non-stationary strategies. I provide a model in which search is sequential and there is a continuum of potential sellers, yet search strategies are stationary because information is communicated credibly using cheap talk. Hence, I show that in principle sequential search among a large number of sellers can be modeled tractably.

The rest of this paper proceeds with Section 2 which presents the model. Section 3 characterizes the full information equilibrium, followed by Section 4 which shows the result that cheap signaling can credibly convey information. Sections 5 and 6 discuss the two policy experiments: a ban on cheap communication and an introduction of price ceilings, respectively. Section 7 then concludes.

\section{The Model}

On the demand side there is a continuum of consumers with measure one. Each consumer demands a single unit of a good. Consumers draw their valuation for the good from a distribution in which with probability $\varphi$ they draw the high value of 1 and with probability $1-\varphi$ they draw the low value $v<1$. The parameter $\varphi$ is uncertain and has two equally likely realizations $\varphi_{L}$ and $\varphi_{H}$. Consumers learn only their own valuation and not the realization of $\varphi$.

The supply side consists of a monopolist manufacturer and a continuum of retailers with measure one. The manufacturer has zero production costs and is restricted to setting a uniform linear wholesale price $w$ for all retailers. Each retailer has constant marginal costs made up of two components: the common wholesale price $w$ and an idiosyncratic cost $c$. Retailers independently draw $c$ from a continuous and differentiable distribution $F(\cdot)$ with support on $[0,1]$.

The game proceeds as follows. First, nature selects $\varphi$ and the realization is observed by the manufacturer and retailers but not by the consumers. The manufacturer then chooses wholesale price $w$ and signal $\sigma \in\left\{\sigma_{L}, \sigma_{H}\right\}^{2}$. Next, retailers, having observed $\varphi, w, \sigma$ and

\footnotetext{
${ }^{2}$ This restriction on the signal space is without loss of generality given that there are two states of nature.
} 
their own cost $c$, simultaneously set prices. These prices are then fixed for the rest of the game. Next, each consumer learns her own valuation and observes the manufacturer's signal $\sigma$ and a price $p$ from a randomly selected retailer. The consumer can purchase the good at price $p$ and exit the market, exit the market without purchasing, or search. If she chooses to search, the consumer pays a search cost $s$, observes another price at a randomly selected retailer, ${ }^{3}$ and at this point has the option to purchase the good at any of the prices she has seen so far, exit without purchasing, or search again. This process continues until every consumer has exited. There is no time discounting.

$\begin{array}{lccc} & & & \\ \varphi \text { realized, } & \text { Manufacturer } & \text { Retailers set } & \text { Consumers } \\ \text { observed by } & \text { sets } & p(c \mid w, \sigma, \varphi) & \text { Time } \\ \text { Manufacturer } & w(\varphi), \sigma(\varphi) & & \\ \text { and Retailers } & & & \end{array}$

Figure 1: Model Timing

Strategies are $w(\varphi), \sigma(\varphi)$ for the manufacturer and $p(c \mid w, \sigma, \varphi)$ for retailers. Define $\overrightarrow{\mathbb{P}}$ as the set of all possible price histories, so that

$$
\overrightarrow{\mathbb{P}} \equiv\left\{\vec{p}=\left\{p_{i}\right\}_{i=1, \ldots, n} \mid n \in \mathbb{I}, p_{i} \in \mathbb{R}^{+}\right\}
$$

Conditional on her valuation $\theta \in\{v, 1\}$, a consumer has strategy $A(\sigma, \vec{p} \mid \theta)$ and beliefs $\mu(\sigma, \vec{p} \mid \theta)$ where

$$
\begin{aligned}
& A:\left\{\sigma_{L}, \sigma_{H}\right\} \times \overrightarrow{\mathbb{P}} \times\{v, 1\} \rightarrow\{\text { exit, purchase, search }\} \\
& \mu:\left\{\sigma_{L}, \sigma_{H}\right\} \times \overrightarrow{\mathbb{P}} \times\{v, 1\} \rightarrow[0,1]
\end{aligned}
$$

I use the Perfect Bayesian Equilibrium solution concept, where all strategies are mutual best responses and beliefs are formed using Bayes rule whenever possible.

\subsection{Model Discussion}

I introduce downstream retailer heterogeneity to induce price dispersion as in Reinganum (1979). On the consumer side, I depart from Reinganum's setting by having heterogenous consumers with unit demand. ${ }^{4}$ The choice of unit demand is motivated in part by the fact that many of the goods that come with price recommendations (cars, electronics, books, etc.) are purchased one at a time as opposed to in continuous quantities. Unit demand also

\footnotetext{
${ }^{3}$ Specifically, I assume that when consumers search they draw every retailer with equal chance.

${ }^{4}$ Reinganum's model has homogeneous consumers with continuous demand. In either case, the key to generating price dispersion is that every retailer has different costs and faces an elastic demand function.
} 
improves tractability while still delivering important qualitative features like downstream price dispersion and search.

The key to ensuring that the manufacturer's signals have content is to endow the manufacturer with information that consumers do not have. I have chosen aggregate demand as the source of uncertainty to reflect the fact that in many markets consumers expect prices to depend on how popular a product may be, and that sellers are more aware of this information than consumers through marketing research or other such means. In principle uncertainty can come from other sources, for instance manufacturer costs. In the conclusion, I will argue that in this scenario there is good reason to believe that the manufacturer can still inform consumers with cheap talk.

As a final note, I find that in equilibrium some retailers do not makes sales due to their high costs and the number of these retailers matters for real market outcomes. I restrict the support of retailer costs to $[0,1]$ in order to include only retailers that can have positive gains from trade.

In the ensuing analysis, I look for an equilibrium in which price recommendations reveal the state via cheap talk. I solve for this equilibrium in two steps. In Section 3, I solve an auxiliary model in which there is complete information about aggregate demand $\varphi$. I then use this solution in Section 4 to help characterize an equilibrium of the main model where the manufacturer's signal perfectly reveals the state to consumers.

\section{Equilibrium in a Full Information Setting}

In this section I solve the model above but as if aggregate demand $\varphi$ is common knowledge. The model is solved backwards by first characterizing the downstream equilibrium between consumers and retailers for some fixed wholesale price $w$ and then use this solution to characterize the manufacturer's optimal choice of $w$.

\subsection{Downstream Equilibrium}

I show that any downstream equilibrium must be of the following form:

- low valuation consumers never search and either buy immediately or quit,

- high valuation consumers use a threshold search strategy $\bar{p}$, and

- retailers makes sales at one of two prices: either $v$ or $\bar{p}$.

To start, in equilibrium consumers know the distribution of prices from which they sample and by a standard result in McCall (1970) they optimally follow stationary threshold strategies. Every consumer has search cost $s$ and one implication of this is that given an equilibrium distribution of prices, if the lowest price charged is $\underline{p}$, no consumer will reject any price $p \in[\underline{p}, \underline{p}+s)$ unless it is bigger than her valuation. 
Next, in any equilibrium the lowest price charged, $\underline{p}$, cannot be smaller than $v$. Toward a contradiction, imagine an equilibrium where $\underline{p}<\bar{v}$. In such an equilibrium no consumer would reject a price $p \in[\underline{p}, \min \{\underline{p}+s, v\})$. This implies that the retailer charging $\underline{p}$ is not maximizing profits: he can increase his price slightly and not lose any sales. Hence, no equilibrium can be supported where a price below $v$ is charged. ${ }^{5}$

In turn, this implies that low valuation consumers will not collect surplus in any equilibrium and consequently never find it optimal to search after their first price observation (which is free). Thus in any equilibrium low valuation consumers either purchase at the first price if it is $v$ or they exit. ${ }^{6}$ High valuation consumers may have incentive to search. Let $\bar{p}$ be their threshold and since no price is ever charged below $v$, it must be that $\bar{p} \geq v+s$.

Now consider the prices set by retailers. Retailers potentially face three kinds of consumers: new low valuation consumers, new high valuation consumers, and high valuation consumers that have already seen some prices but continued to search. Retailers face a step demand function: they can set a price $p \leq v$ and serve all the consumers that visit them or they can set a price $p \in(v, \bar{p}]$ and serve only the high types. A price $p>\bar{p}$ would result in no sales. Letting $\varphi \kappa$ be the number of high type searchers that visit any particular retailer, with $\kappa$ later defined, the retailer's demand function is

$$
q(p)=\left\{\begin{array}{cl}
1+\varphi \kappa & \text { if } p \leq v \\
\varphi+\varphi \kappa & \text { if } v<p \leq \bar{p} \\
0 & \text { if } p>\bar{p}
\end{array}\right.
$$

and is illustrated in Figure 2.

Retailers choose price $p$ to maximize their profit, given by

$$
\pi(p \mid c)=(p-c-w) q(p)
$$

Any retailer with a cost $c>\bar{p}-w$ is priced out of the market. For the purpose of exposition, I assume that all priced out retailers charge a price $p=\infty .^{7}$ Retailers that can afford to participate then charge either $v$ or $\bar{p}$ depending on their cost. Define $\bar{c}$ as the cost at which

\footnotetext{
${ }^{5}$ This argument is adapted for this setting from its original version in Diamond (1971).

${ }^{6}$ Low valuation consumers are actually indifferent between buying at price $v$ or exiting. However, for a technical reason no equilibrium can be supported when low valuation consumers reject $v$ with positive probability. Given $v$ is the low types' threshold, if they reject $v$ with probability $\varepsilon>0$, there always exists a $\delta>0$ small enough where a retailer can charge $v-\delta$, gain the $\varepsilon$ in sales, and make higher profits. A retailer's best response is to choose the highest price from the set of prices strictly smaller than $v$, but since this is an open set no such price exists. So by a closure problem an equilibrium cannot be supported for any $\varepsilon>0$. By the same logic, high valuation consumers must accept with probability 1 at their threshold as well.

${ }^{7}$ In any equilibrium in the full information setting where the highest accepted price is $\bar{p}$, the set of prices set by priced out retailers does not affect any equilibrium outcomes.
} 


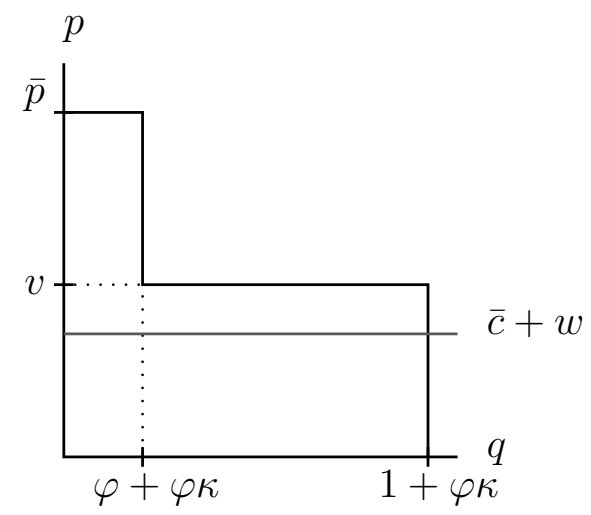

Figure 2: Retailer demand

a retailer is indifferent between these two prices:

$$
\pi(v \mid \bar{c})=\pi(\bar{p} \mid \bar{c}) \quad \Leftrightarrow \quad \bar{c}=v-w-\frac{\varphi}{1-\varphi}(\bar{p}-v)(1+\kappa)
$$

If the $\bar{c}$ that solves equation (1) is negative, it must be that all retailers prefer to charge the higher price $\bar{p}$. Figure 3 illustrates an equilibrium distribution of prices when $\bar{c}>0$.

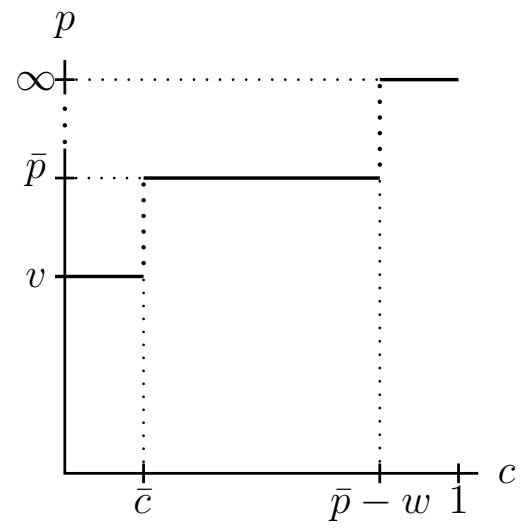

Figure 3: Downstream prices

To this point the structure of the equilibrium has been established: consumers follow a threshold strategy that depends on their valuations and retailers follow a threshold strategy that depends on their cost. The low types' threshold has already been shown to be their valuation $v$, now it remains to solve for thresholds $\bar{p}$ and $\bar{c}$.

Let $V(p)$ be the high type's value function given that $p$ is the lowest price she has seen. By definition,

$$
V(p)=\max \left\{0,1-p, V^{s}(p)\right\}
$$

where the consumer's options are to exit, accept $p$, or continue to search and receive continuation value $V^{s}(p) \equiv E\left[V\left(p^{\prime}\right) \mid p\right]-s$. Given the distribution of equilibrium prices summarized 
by $\bar{c}$, in equilibrium the high type's threshold must satisfy

$$
\begin{aligned}
1-\bar{p} & =\max \left\{0, V^{s}(\bar{p})\right\} \\
& =\max \{0, F(\bar{c})(1-v)+(1-F(\bar{c}))(1-\bar{p})-s\}
\end{aligned}
$$

The left hand side is the value to accepting $\bar{p}$ and the right hand side gives the maximum of either the value of exiting or the continuation value of searching. When continuing to search, a consumer will pay cost $s$ and observe price $v$ with probability $F(\bar{c})$ or a price at least as high as $\bar{p}$ with probability $1-F(\bar{c})$. If $v$ is observed, the consumer will accept it and obtain payoff $1-v$. If a price of $\bar{p}$ or higher is observed the continuation payoff to the consumer is $1-\bar{p}$ since she is indifferent to accepting $\bar{p}$ at that point. When $\bar{p}<1$ solves the equation above, the expression simplifies to

$$
(\bar{p}-v) F(\bar{c})=s
$$

This gives a natural interpretation for the threshold, with the left hand side being the expected benefit from another observation and the right hand side being the expected cost.

With $\bar{p}$ defined, it is also necessary to specify a high type's behavior when she observes a price above $\bar{p}$. Since search is costly, she may find it optimal to either continue to search or exit depending on the distribution of prices. Having observed only prices above $\bar{p}$, a consumer's continuation value to searching is

$$
\begin{aligned}
V^{s}(p \geq \bar{p}) & =F(\bar{c})(1-v)+(F(\bar{p}-w)-F(\bar{c}))(1-\bar{p}) \\
& +(1-F(\bar{p}-w)) \max \left\{0, V^{s}(p \geq \bar{p})\right\}-s
\end{aligned}
$$

That is, a consumer can either observe and accept a price of $v$ or $\bar{p}$ or observe a higher price and have the option to search or exit. ${ }^{8}$ Let $\alpha$ be the probability with which a consumer searches conditional on rejecting. When $\bar{p}<1$ solves equation (3), the continuation value to searching must be strictly positive, hence $\alpha=1$. When $\bar{p}=1$, that is when high type consumers accept any price at or below their valuation, the continuation value to searching is either exactly zero or strictly negative (see equation (2)). In this case equation (5) simplifies to

$$
V^{s}(p \geq \bar{p}=1)=F(\bar{c})(1-v)-s
$$

If $F(\bar{c})(1-v)-s<0$ exiting is strictly preferred to searching so $\alpha=0$. If $F(\bar{c})(1-v)-s=0$, then any $\alpha \in[0,1]$ is optimal for the consumer. To summarize, $\alpha$ must satisfy

$$
\alpha= \begin{cases}1 & \text { if } \bar{p}<1 \\ 0 & \text { if } \bar{p}=1, F(\bar{c})(1-v)-s<0\end{cases}
$$

\footnotetext{
${ }^{8}$ Note that implicit in equation $(5)$ is the fact $V^{s}(p \geq \bar{p})$ is constant in $p$. This is a standard result, stemming from the fact that having access to a price one will never accept in the future provides the same continuation value regardless of what that price actually is.
} 
Lastly, the equilibrium must specify the number of searchers $\varphi \cdot \kappa$ received by each retailer. The probability that a high type consumer rejects her first price but eventually purchases is given by

$$
\operatorname{Pr}(\text { search and buy })=F(\bar{p}-w) \sum_{i=1}^{\infty}(\alpha(1-F(\bar{p}-w)))^{i}=F(\bar{p}-w) \frac{\alpha(1-F(\bar{p}-w)}{1-\alpha(1-F(\bar{p}-w)}
$$

Since consumers are equally likely to visit every retailer on any draw, in equilibrium all participating retailers serve the same number of searchers. Hence,

$$
\kappa=\frac{\operatorname{Pr}(\text { search and buy })}{F(\bar{p}-w)}=\frac{\alpha(1-F(\bar{p}-w)}{1-\alpha(1-F(\bar{p}-w)}
$$

Note than when $\alpha=1$ and high types continue to search until they buy, this expression reduces to $\kappa=(1-F(\bar{p}-w)) / F(\bar{p}-w)$, that is the ratio of the number of retailers that induce searchers and the number that receive searchers. When $\alpha=0, \kappa=0$ since high types either purchase at the first retailer or exit. The retailer's threshold can now be directly expressed as a function of high types' strategy $\bar{p}$ and $\alpha$ and is given by

$$
\bar{c}=v-w-\frac{\varphi}{1-\varphi} \frac{\bar{p}-v}{1-\alpha(1-F(\bar{p}-w))}
$$

With consumer behavior described by equations (3) and (6) and retailers' prices described by equation (8), the following proposition summarizes the structure of the downstream equilibrium.

Proposition 1 Under full information, any downstream equilibrium is characterized by thresholds $\bar{p}$ and $\bar{c}$, and probability $\alpha$ that satisfy equations (3), (6), and (8) with strategies as follows:

- low valuation consumers accept any $p \leq v$, else they exit

- high valuation consumers accept any $p \leq \bar{p}$, else they search with probability $\alpha$ and exit with probability $1-\alpha$

- retailers set prices according to

$$
p(c)= \begin{cases}v & c \in[0, \bar{c}] \\ \bar{p} & c \in(\bar{c}, \bar{p}-w] \\ \infty & c \in(\bar{p}-w, 1]\end{cases}
$$

Furthermore, a downstream equilibrium always exists.

That any equilibrium must be characterized in this way follows from the line of argument presented in preceding text. Existence can be proven by showing that equations (3) and (8) must intersect and the formal proof can be found in Appendix A. 
Lastly, note that while the equilibrium must be of the form described in Proposition 1, there may still be multiple equilibria. This is due to the complementarity between $\bar{c}$ and $\bar{p}$. A higher search threshold can lead to fewer retailers charging $v$ which can then justify the increased search threshold. For clarity of exposition I restrict attention to the downstream equilibrium with the lowest prices.

\subsection{Upstream Decision}

With downstream behavior characterized, I now solve for the manufacturer's optimal wholesale price. It is important here to recall the information structure, in particular that while retailers observe and react to the wholesale price $w$, consumers only observe retail prices. Hence, the manufacturer knows that although changing the wholesale price affects the prices set by retailers (as summarized by $\bar{c}$ ), it would not affect the search threshold $\bar{p}$ or search probability $\alpha$ of the high valuation consumers.

The demand function faced by a manufacturer is given by

$$
\begin{aligned}
Q(w) & =\underbrace{(1-\varphi) F(\bar{c}(w))}_{\text {sales to low types }}+\underbrace{\varphi F(\bar{p}-w)(1+\kappa(w))}_{\text {sales to high types }} \\
& =(1-\varphi) F(\bar{c}(w))+\varphi \frac{F(\bar{p}-w)}{1-\alpha(1-F(\bar{p}-w))}
\end{aligned}
$$

The first term is the total sales to low types and this object decreases in $w$. Note from equation (8) that

$$
\frac{\partial \bar{c}}{\partial w}=-1-\frac{\varphi}{1-\varphi}(\bar{p}-v) \frac{\alpha f(\bar{p}-w)}{1-\alpha(1-F(\bar{p}-w))}<0
$$

That fewer retailers serve low types at a higher wholesale price is a consequence of two effects: a higher wholesale price reduces markups and also increases the number of searchers by excluding more retailers. Both effects make charging the higher $\bar{p}$ relatively more attractive. This can be thought of as the double marginalization effect, which in the vertical markets literature refers to the idea that retailers use their market power to charge markups above their costs. In this setting, a retailer's market power derives from the search friction and the decision to switch to charging $\bar{p}$ rather than $v$ reflects the use of this power.

The second term in the demand function is the total sales to high types. Here the probability $\alpha$ that high types continue to search plays an important role. When $\alpha=1$, the manufacturer's demand reduces to

$$
Q(w \mid \alpha=1)=(1-\varphi) F(\bar{c}(w))+\varphi \cdot \mathbb{I}(w<\bar{p})
$$

Recall that consumers do not observe the wholesale price. Rather, their only information comes from the prices they observe when searching. Given an equilibrium in which $\alpha=1$, 
high type consumers never exit and continue to search until they see a price below their threshold $\bar{p}$. A manufacturer can take advantage of this behavior by increasing his wholesale price to a point at which very few retailers remain in the market. In this situation high type consumers would eventually purchase, but only after searching for a long time. Consumers cannot, from the length of their search, infer that the manufacturer has increased his wholesale price, instead they interpret a long sequence of very high prices as bad luck.

Figure 4 illustrates a downstream demand function $Q(w \mid \alpha=1, \bar{p})$, assuming that when $w=0$ some retailers sell to low types. The figure is meant only to show manufacturer incentives conditional on the strategy $(\alpha=1, \bar{p})$ of high type consumers; it has not yet been shown that it represents an equilibrium.

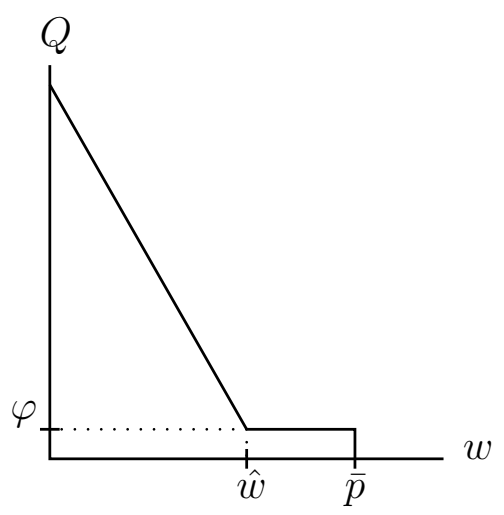

Figure 4: Downstream demand when $\alpha=1$

The downward sloping part of the demand curve corresponds to wholesale prices that induce sales to both high and low type consumers. From equation (10), as the wholesale price $w$ increases, sales to low types fall because $\frac{\partial \bar{c}}{\partial w}<0$, and sales to high types remain unchanged. The demand curve kinks at the wholesale price $\hat{w}$ where $\bar{c}(\hat{w})=0 .{ }^{9}$ For higher wholesale prices, all high types continue to be served and thus the demand curve is flat. Once $w>\bar{p}$, no retailers can afford to serve the high types and the manufacturer induces no sales. Note also that as Figure 4 is drawn, $\varphi$ is relatively small and consequently the optimal $w$ falls in the region in which both high and low types are served. That this is actually true in equilibrium will proven later in this section.

Next consider the manufacturer's decision when high types do not always search, i.e. $\alpha<1$. Then demand is given by

$$
Q(w \mid \alpha<1)=(1-\varphi) F(\bar{c}(w))+\varphi \frac{F(\bar{p}-w)}{1-\alpha(1-F(\bar{p}-w))}
$$

In this case not all high type consumers are served. Every time consumers visit a retailer that is priced out they exit the market with chance $1-\alpha$. For example, when $\alpha=0$ the

\footnotetext{
${ }^{9}$ By equation (1) for any $\bar{p}$ there exists a $w$ at which $\bar{c}=0$.
} 
manufacturer is only able to sell to high types with probability $F(\bar{p}-w)$. Figure 5 shows an example of such a demand function, $Q(w \mid \alpha=0, \bar{p}=1)$, with a uniform distribution of retailer costs $F$. Again, the same caveat as in Figure 4 applies in that the consumer behavior is taken as given and not shown to be an equilibrium behavior.

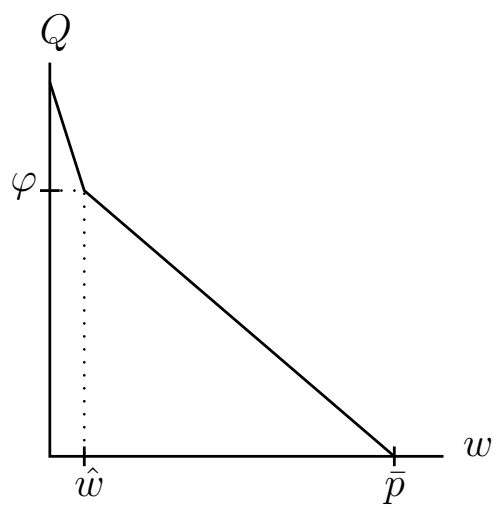

Figure 5: Downstream demand when $\alpha=0$

There is still a kink in the demand curve at the wholesale price $\hat{w}$ at which $\bar{c}(\hat{w})=0$ and low types are no longer served. However, beyond this point increasing the wholesale price continues to result in a loss of sales. Again, as Figure 5 is drawn, the number of high types $\varphi$ is sufficiently large so that the optimal wholesale price falls in the region in which only high types are served.

It is important for the later cheap talk result that in fact Figures 4 and 5 do depict equilibrium objects. That is, when demand $\varphi$ is small enough the manufacturer serves all types in equilibrium and induces search while when demand is large enough the manufacturer serves only high types in equilibrium. This proposition is stated below with the proof relegated to Appendix B.

Proposition 2 The full information equilibrium is characterized by Proposition 1 and wholesale price $w=\arg \max w \cdot Q(w)$, as given by equation (9). Furthermore, when aggregate demand $\varphi$ and search cost $s$ are sufficiently small, low types are served in equilibrium and high types search until they purchase. When $\varphi$ is sufficiently large no search is induced and low types are excluded.

\section{Cheap Signaling}

Having solved the full information model, that analysis can now be used to help characterize the equilibrium with cheap communication. I look for an equilibrium in which consumers learn the aggregate demand $\varphi$ immediately upon observing the recommendation $\sigma$ at the first retailer that they visit. In such an equilibrium, consumers act as if they are fully informed. But for this to be an equilibrium, when given the opportunity the manufacturer cannot have 
incentive to mislead consumers. That is, given that the manufacturer can induce consumers to search as if it were the high state or as if it were the low state, it needs to be verified that he will choose to signal truthfully in both states. Changing consumers' search behavior through the cheap signal amounts to a shift of the demand function faced by the manufacturer, hence showing that truthful signaling is optimal requires showing that the payoff the manufacturer obtains in the full information equilibrium is higher than the payoff he would obtain for any wholesale price were he to send a false signal. Cheap signaling is not always credible, instead the aim is to show that cheap signaling is possible and to highlight the conditions under which cheap signaling can arise.

First, having switched back to a game of incomplete information it is now necessary to specify consumers' beliefs. A high type consumer's belief that aggregate demand is high, $\mu(\sigma, \vec{p})$, depends on the manufacturer's signal $\sigma$ and the set of prices she has observed thus far $\vec{p}$. In an equilibrium in which signals reveal the state, beliefs must be consistent with equilibrium play so that $\mu\left(\sigma_{H}, \vec{p}\right)=1$ and $\mu\left(\sigma_{L}, \vec{p}\right)=0$ for all price vectors $\vec{p}$ on the equilibrium path. ${ }^{10}$ However, off the equilibrium path beliefs are unrestricted and this can lead to consumers pursuing a non-stationary search strategy. ${ }^{11}$ To address this, I restrict attention to equilibria in which a consumer's beliefs are $\mu\left(\sigma_{H}, \cdot\right)=1$ and $\mu\left(\sigma_{L}, \cdot\right)=0$. This implies that when a consumer sees a price and signal combination that are inconsistent, she trusts the manufacturer's signal.

Given this restriction on beliefs, consumers act as if they are fully informed about the state. Retailers anticipate consumers' behavior as a function of recommendation $\sigma$, and since retailers expect consumers to still follow threshold strategies, they still set retail prices according to equation (8). I now consider the manufacturer's incentives for revealing truthfully.

Let $\left(\bar{p}_{L}, \alpha_{L}\right)$ and $\left(\bar{p}_{H}, \alpha_{H}\right)$ be the search strategies employed by consumers in the full information equilibrium in the low and high demand state, respectively. I focus on parameters such that under full information, search is induced in the low demand state $\left(\alpha_{L}=1, \bar{p}_{L}<1\right)$ but not in the high demand state $\left(\alpha_{H}=0, \bar{p}_{H}=1\right)$. By Lemmas 9 and 10, this requires that $\varphi_{L}$ and $s$ are sufficiently small and $\varphi_{H}$ is sufficiently large. To prove the existence of a cheap talk equilibrium, I verify that conditional on being in the high demand state, the manufacturer is better off inducing $\left(\bar{p}_{H}, \alpha_{H}\right)$ than $\left(\bar{p}_{L}, \alpha_{L}\right)$ and vice versa in the low demand state. In doing this, it is important to remember that retailers are aware of the true state. While in equilibrium consumers' beliefs and hence their search behavior change in response to the manufacturer's signal, retailers know the true state and respond to the signal only in anticipation of the consumers' actions. That is, the threshold retailer $\bar{c}(w, \varphi, \bar{p}(\sigma), \alpha(\sigma))$ depends on the wholesale price $w$, the true state $\varphi$, and the anticipated consumer behavior

\footnotetext{
${ }^{10}$ Formally, given an equilibrium price distribution $G(p)$, any price $p$ is on the equilibrium path if $\lim _{\varepsilon \rightarrow 0} \frac{G(p+\varepsilon)-G(p-\varepsilon)}{2 \varepsilon}>0$.

${ }^{11}$ As an example suppose the manufacturer sends signal $\sigma_{L}$ and consider a price path $\vec{p}=\left\{p_{1}, p_{2}\right\}$ in which price $p_{1}$ is on the equilibrium path but $p_{2}$ is not. Since off the equilibrium path beliefs are unrestricted, suppose $\mu\left(\sigma_{L},\left\{p_{1}, p_{2}\right\}\right)=1$. Then the consumer would be using one threshold strategy $\bar{p}_{L}$ after observing $p_{1}$ and a different threshold strategy $\bar{p}_{H}$ after observing $\left\{p_{1}, p_{2}\right\}$.
} 
$\bar{p}(\sigma)$ and $\alpha(\sigma)$.

First, suppose that aggregate demand is high. By sending signal $\sigma_{H}$ and revealing the high state, the manufacturer earns a profit

$$
\begin{aligned}
\Pi^{*}\left(\sigma_{H} \mid \varphi_{H}\right) & =\max _{w} w \cdot Q\left(w, \sigma_{H} \mid \varphi_{H}\right) \\
& =\max _{w} w\left(\left(1-\varphi_{H}\right) F\left(\bar{c}\left(w, \varphi_{H}, 1,0\right)\right)+\varphi_{H} \cdot F(1-w)\right)
\end{aligned}
$$

The downstream demand is given by equation (11), and by assumption $\alpha_{H}=0$ and $\bar{p}_{H}=1$. That is, by signaling the high demand state the manufacturer induces consumers to either accept their first observed price or exit. If the manufacturer were instead to send the false signal $\sigma_{L}$, he would induce $\bar{p}_{L}<1$ and $\alpha_{L}=1$ and obtain a profit

$$
\begin{aligned}
\Pi^{*}\left(\sigma_{L} \mid \varphi_{H}\right) & =\max _{w} w \cdot Q\left(w, \sigma_{L} \mid \varphi_{H}\right) \\
& =\max _{w} w\left(\left(1-\varphi_{H}\right) F\left(\bar{c}\left(w, \varphi_{H}, \bar{p}_{L}, 1\right)\right)+\varphi_{H} \cdot \mathbb{I}\left(w \leq \bar{p}_{L}\right)\right)
\end{aligned}
$$

The above demand function follows from equation (10). When sending his signal, the manufacturer thus induces one of two demand functions, as depicted in Figure 6, in which retailers' costs are distributed uniformly.

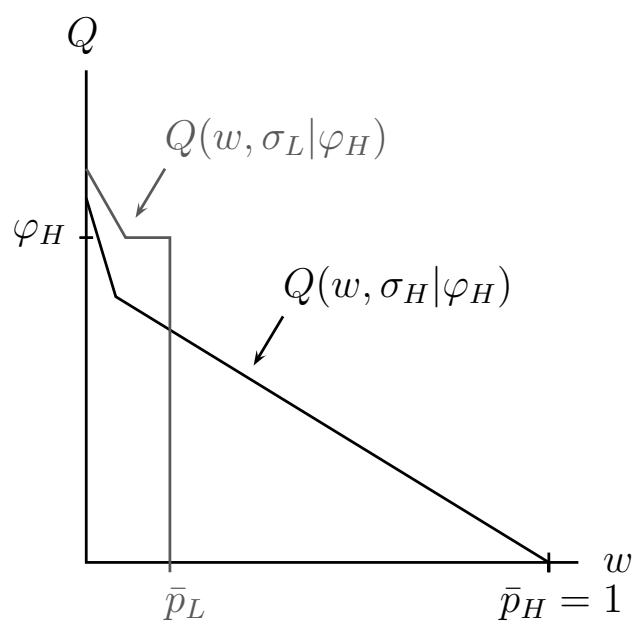

Figure 6: Signaling in state $\varphi_{H}$

When the manufacturer signals the high state with $\sigma_{H}$, he faces the same demand as in Figure 5 in the full information equilibrium. If the manufacturer falsely signals the low state, he induces the lower search threshold $\bar{p}_{L}$ but also induces high types to search instead of exiting. As a result, by falsely signaling $\sigma_{L}$ it is possible that the manufacturer can serve more consumers for wholesale prices below $\bar{p}_{L}$. However $\bar{p}_{L}$ also acts as a wholesale price ceiling on the manufacturer. The exercise is to show that there are parameters for which $\bar{p}_{L}$ is small and thus restrictive, while for those same parameters the maximized profit from truthfully signaling $\sigma_{H}$ remains relatively high. 
Lemma 3 Given $\varphi_{H}$ is high enough so that no low valuation consumers are served under full information, if $s, \varphi_{L}$, and $v$ are sufficiently small then the manufacturer prefers to reveal the high demand state truthfully.

Sketch of Proof Using the fact that $\alpha_{L}=1$ and $\bar{p}_{L}<1$, re-arrange equation (3) to get

$$
\bar{p}_{L}=v+\frac{s}{F\left(\bar{c}_{L}\right)}
$$

Note that $\bar{c}_{L}$ is an equilibrium object that depends in part on the values $v$ and $s$. I show in Appendix $\mathrm{C}$ that when $s, v$, and $\varphi_{L}$ are appropriately small, the full information $\bar{p}_{L}$ is arbitrarily close to 0 , which makes $\Pi^{*}\left(\sigma_{L}, \varphi_{H}\right)$ also arbitrarily close to zero. To get some intuition for this, consider the extreme case with $s=0$. Here, all consumers will use threshold $\bar{p}=v$, and thus as $v$ is reduced toward zero, so is the equilibrium $\bar{p}$. At the same time, fixing those values of $v$ and $s$, for any $\varphi_{H}$ the profit to truth telling $\Pi\left(\sigma_{H}, \varphi_{H}\right)$ is bounded from below by $\max _{w} w \cdot \varphi_{H} F(1-w)>0$. Hence inducing $\bar{p}_{L}$ will reduce profits.

Next consider the low demand state $\varphi_{L}$. Here, the argument will be that when demand is low enough the manufacturer's optimal wholesale price will induce sales to low types regardless of which signal he sends. It will then be shown that for any wholesale price that induces sales to low types, demand is higher when the signal $\sigma_{L}$ is sent. Figure 7 depicts this situation.

First it follows from equation (9) that regardless of search behavior $\alpha$ and search threshold $\bar{p}>v$, when $\varphi$ is sufficiently small, that is when consumers are overwhelmingly of low type, the manufacturer will find it optimal (and feasible) to set a wholesale price low enough to induce sales to low types.

It needs to be shown that for any wholesale price that includes low types, total sales are higher with signal $\sigma_{L}$. Consider first sales to high types. Since $\alpha_{L}=1$ every high type is eventually served while under $\alpha_{H}=0$ some high types will exit prior to finding a price to which they would agree. Thus sales to high types are unambiguously higher.

Sales to low types are higher under signal $\sigma_{L}$ if they induce a higher threshold $\bar{c}$ for retailers. The difference in $\bar{c}$ under the two signals is given by

$$
\bar{c}\left(w, \varphi_{L}, \bar{p}_{L}, 1\right)-\bar{c}\left(w, \varphi_{L}, 1,0\right)=\frac{\varphi_{L}}{1-\varphi_{L}}\left(1-v-\frac{\bar{p}_{L}-v}{F\left(\bar{p}_{L}-w\right)}\right)
$$

By the proof in Appendix C, the expression $\frac{\bar{p}_{L}-v}{F\left(\bar{p}_{L}-w\right)}$ can be made arbitrarily small by choosing appropriately small values for $\varphi_{L}$ and $s$. Hence, for small enough $\varphi_{L}$ and $s$, it must be that $\bar{c}\left(w, \varphi_{L}, \bar{p}_{L}, 1\right)>\bar{c}\left(\tilde{w}, \varphi_{L}, 1,0\right)$ and thus at every $w$ that induces sales to low types sending the signal $\sigma_{L}$ increases sales to low types. As a result, we obtain the following Lemma.

Lemma 4 Whenever $\varphi_{H}$ is sufficient large, if search cost $s$ and low state aggregate demand $\varphi_{L}$ are sufficiently small then the manufacturer prefers to reveal the low demand state truthfully. 


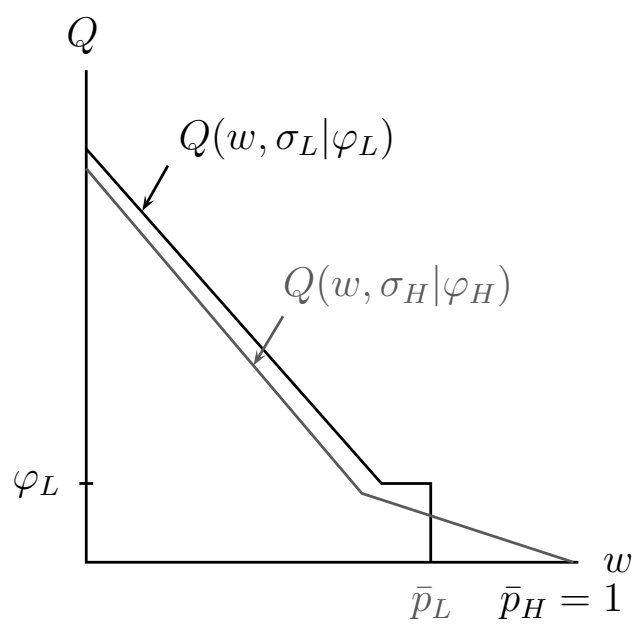

Figure 7: Signaling in state $\varphi_{L}$

All that remains to check is that there exist parameter values that satisfy the conditions for truth telling in the low state and the high state. By inspection of the two preceding lemmas, as long as the low state is characterized by a small enough $\varphi_{L}$ and $v$, the high state is characterized by a large enough $\varphi_{H}$, and the search cost $s$ is sufficiently small, signaling can be credible in both states.

Proposition 5 The manufacturer can credibly communicate via cheap talk when search cost $s$ is sufficiently small, $\varphi_{H}$ is sufficiently high and $v$ and $\varphi_{L}$ are sufficiently low.

The intuition behind why the manufacturer could credibly signal comes from understanding the impact of increasing the search threshold $\bar{p}$ on the manufacturer's demand function $Q(w)$. Increasing $\bar{p}$ worsens double-marginalization and reduces sales wholesale prices designed to serve low types. However, a higher $\bar{p}$ also means that a higher price is available at which high types can be served, and if the manufacturer intends to set a high wholesale price a higher $\bar{p}$ is beneficial.

Having established that it is possible that price recommendations can act as cheap signals that inform consumers about aggregate demand, I now consider the implications of a policy that would prohibit the manufacturer from doing so.

\section{The Effects of a Ban on Recommendations}

The ability to make price recommendations endows the manufacturer with some indirect control of downstream prices. This practice can be considered a type of vertical restraint and a natural question from an antitrust perspective is what would happen if such signaling were banned.

Without recommendations the model becomes substantially more difficult to solve as consumers' search strategies are now non-stationary and every observed price can change a 
consumer's beliefs about whether it is the high or low demand state. Retailers in turn would face consumers that hold heterogeneous beliefs and possibly different search thresholds. This paper will not characterize the set of equilibria with no signaling, thus a welfare effect of a ban on recommendations is not derived in general. However, a set of parameters is identified that both guarantees credible signaling and provides a tractable solution to the no-signaling equilibrium, and in these situations a clear welfare implication emerges.

In solving for the no-signaling equilibrium, the key is the belief of a consumer that has learned her type but not yet observed any prices. If a consumer learns that she has a high type, her belief is

$$
\mu_{0}=\frac{\varphi_{H}}{\varphi_{H}+\varphi_{L}}
$$

with associated likelihood ratio $\lambda_{0}=\frac{\varphi_{H}}{\varphi_{L}}$. Consequently, every high valuation consumer is overly pessimistic about aggregate demand (in the sense that high demand implies high prices) and every low valuation consumer is overly optimistic. Since it is only the high valuation consumers that search, consumers may search less on average than they ought to.

I focus on a setting in which $\lambda_{0}$ is a large number. Specifically, let $\varphi_{H}$ be high enough so that the manufacturer finds it optimal to sell only to high types and $\varphi_{L}$ be low enough so that the manufacturer finds it optimal to sell to all types.

Recall that $\vec{p}=\left\{p_{1}, \ldots, p_{n}\right\}$ represents a sequence of observed prices and $\mu(\vec{p})$ is the high valuation consumer's belief conditional on having observed $\vec{p}$. For tractability as well as to be consistent with the assumption made in the model with recommendations, I consider only equilibria in which price observations off the equilibrium path do not alter beliefs. Formally, restrict attention to equilibria with

$$
\mu\left(\left\{p_{i}\right\}_{i=1, \ldots, n}\right)=\mu\left(\left\{p_{j}\right\}_{j \in E}\right) \text { where } E=\left\{i \mid p_{i} \text { is on the equilibrium path }\right\}
$$

In addition, I look only for equilibria in which retailers that do not make sales convey no information beyond the fact that they are priced out. Specifically, if a retailer has costs $w+c$ and in equilibrium demand at any $p \geq w+c$ is zero, then the retailer charges $p=\infty$.

I define a "no search equilibrium" to be an equilibrium of the following form. In the low demand state retailers charge either $v$ or 1 , in the high demand state retailers charge only 1. Consumers do not search after their first price draw and either accept or exit. Beliefs off the equilibrium path at all prices other than $v$ or 1 are $\mu=\frac{\varphi_{H}}{\varphi_{H}+\varphi_{L}}$ by the assumption above.

Lemma 6 When signaling is banned, the no search equilibrium is supported whenever $\varphi_{H}$ is sufficiently large and $\varphi_{L}$ is sufficiently small.

The proof can be found in Appendix D. The idea of the proof is that when a high type's prior belief $\frac{\varphi_{H}}{\varphi_{L}}$ is sufficiently high and thus pessimistic, she will not find it optimal to search and will exit if her first observation is at a retailer that is priced out. 
Recall that to support a cheap talk equilibrium, it must be that $\varphi_{L}, v$, and $s$ are sufficiently small and $\varphi_{H}$ is sufficiently large. Given that the requirement to support the no search equilibrium is also that $\varphi_{H}$ is sufficiently large and $\varphi_{L}$ is sufficiently small, there exist parameter values where both of these equilibria are supported. I focus my analysis on this set of parameters.

Let the equilibrium with cheap signaling be described by

$$
\left(\left(w_{L}^{s}, \bar{c}_{L}^{s}, \bar{p}_{L}^{s}, \alpha_{L}^{s}\right),\left(w_{H}^{s}, \bar{c}_{H}^{s}, \bar{p}_{H}^{s}, \alpha_{H}^{s}\right)\right)
$$

In the low state search is induced and thus $\bar{p}_{L}^{s}<1$ and $\alpha_{L}^{s}=1$, and low types are served so that $\bar{c}_{L}^{s}>0$. In the high demand state sales are made only to high types and there is no search, thus $\bar{c}_{H}^{s} \leq 0, \bar{p}_{H}^{s}=1$, and $\alpha_{H}^{s}=0$. In the no search equilibrium when signaling is banned, consumers do not search and either purchase immediately or exit and manufacturer and retailer strategies are described by

$$
\left(w_{L}^{n s}, \bar{c}_{L}^{n s}, w_{H}^{n s}, \bar{c}_{H}^{n s} ; \bar{p}^{n s}=1, \alpha^{n s}=0\right)
$$

In this equilibrium sales are made to low types only in the low state, thus $\bar{c}_{L}^{n s}>0$ and $\bar{c}_{H}^{n s} \leq 0$.

Having defined the equilibria across the two regimes, let us compare the outcomes. In the high demand state, both in the signaling and no signaling cases outcomes are identical. Downstream, consumers do not search and $\varphi_{H}$ is high enough that for any $w$, retailers that make sales all charge a price of 1 . This implies that the manufacturer faces the same downstream demand function in both situations, and sets a wholesale price that solves

$$
w_{H}^{s}=w_{H}^{n s}=\arg \max _{w} w \cdot \varphi_{H} F(1-w)
$$

In the low demand state several differences emerge. First under no signaling fewer low types are served. This is because serving only high types is relatively more attractive since $\bar{p}_{L}^{s}<\bar{p}^{n s}=1$. Also, fewer high valuation consumers are served when signaling is banned. With signaling every high valuation consumer purchases in the low state but with the ban, high valuation consumers purchase with probability $F\left(\bar{p}_{L}^{n s}-w_{L}^{n s}\right)<1$. In addition, with no signaling those consumers that purchase do so from retailers with costs that are higher on average, since retailers with costs $c \in\left[\bar{p}_{L}^{s}-w_{L}^{s}, 1-w_{L}^{n s}\right]$ can now make sales. Both reduced sales to high and low types and the increase in the average retailer costs diminish welfare. On the other hand, a ban on signaling does allow high valuation consumers that quit to save on search costs. For a high type consumer, the expected total cost of searching in a setting with signaling is given by

$$
\sum_{i=1, \ldots, \infty}\left(\left(1-F\left(\bar{p}_{L}^{s}-w_{L}^{s}\right) \cdot s\right)^{i} F\left(\bar{p}_{L}^{s}-w_{L}^{s}\right)=F\left(\bar{p}_{L}^{s}-w_{L}^{s}\right) \frac{\left(1-F\left(\bar{p}_{L}^{s}-w_{L}^{s}\right) s\right.}{1-\left(1-F\left(\bar{p}_{L}^{s}-w_{L}^{s}\right) s\right.}\right.
$$

Expected total search cost becomes arbitrarily small with a shrinking $s$. At the same time, conditional on consumers not searching both the strategies of the retailers and the manufacturer do not vary with $s$. Thus, as $s$ falls the savings on search costs associated with a ban 
on signaling fall while the welfare losses due to fewer sales and higher average costs remain unchanged. For small enough $s$, the losses must dominate.

Lemma 7 For parameter values that support a cheap talk equilibrium and an equilibrium with no search without signaling, when search cost $s$ is sufficiently small welfare is higher in the cheap talk equilibrium than in the no search equilibrium.

The proof is omitted but follows along the lines of the preceding arguments.

Another way to examine the ban on recommendations is to consider its effect on the individual parties. The manufacturer is made unambiguously worse off. If the high state ensues the manufacturer is indifferent, however in the low state the outcome is as if the manufacturer successfully lies about the state to consumers, which by the cheap talk result is not in the manufacturer's interest. Low valuation consumers are equally well off as they receive zero surplus under either scenario. High valuation consumers are worse off with the ban; they receive zero surplus in the low state whereas with signaling they expect positive surplus. The effect on retailers as a group is ambiguous. Retailers that are priced out in the setting with recommendations can now make sales since $\bar{p}$ has increased to 1 . But retailers with low costs make fewer sales, both due to the fact that some consumers are now served by higher cost retailers and because they receive no searchers.

\section{A Comparison of Recommendations and Price Ceil- ings}

Most products sell at or below their recommended price, and consequently recommendations have often been treated as binding price ceilings in the literature (Gill and Thanassoulis (2010)). While I present an alternative explanation in which recommendations communicate information, the equilibrium is still observationally equivalent to a situation in which the manufacturer sets a price ceiling $\bar{p}_{L}$ and $\bar{p}_{H}$ in each state. At the same time, in my model the manufacturer can only induce $\bar{p}_{L}$ or $\bar{p}_{H}$ and not any other ceiling. The question is are recommendations just a poor substitute for price ceilings?

In this section I present an informal argument that the answer to this question is no, that in fact recommendations may allow a manufacturer to achieve outcomes unattainable with price ceilings alone. The essence of the argument is a distinction between information and control.

To this end, consider a setting as in the previous section in which the manufacturer is unable to communicate with consumers in any way but now can also set a binding price ceiling $p^{c}$ for retailers. While consumers do not observe the ceiling ${ }^{12}$, in equilibrium they hold beliefs about the ceiling in each state that match equilibrium strategies. What I present

\footnotetext{
${ }^{12}$ If $p^{c}$ were public, consumer could infer from it aggregate demand, hence the ceiling would serve both as information and control and should in principle do at least as well as information alone.
} 
here is an informal argument suggestive of the fact that control is not quite enough.

Consider a set of parameters that supports a no-search equilibrium from the previous section. Without price ceilings, recall that in equilibrium retailers charge $v$ and 1 in the low state and only 1 in the high state. As argued in Lemma 6, a no-search equilibrium is supported because high types are convinced that it is a high demand state, in which case the returns to searching are zero. With this in mind, one may conjecture that for these parameters an equilibrium with search can be supported if the manufacturer sets a price ceiling $p^{c}<1$ in the high state. Doing so would then give returns to searching in the high state, and thus even agents that are pessimistic would continue searching until they find an acceptable price.

However this equilibrium would be quite difficult to support. The issue is commitment by the manufacturer. Suppose with some price ceiling $p^{c}$ the manufacturer induces the search behavior $\alpha=1$ so that no consumer ever exits. If in the high demand state the manufacturer looks to serve only high types, then he has incentive to eat into the returns to searching by, for instance, increasing his wholesale price almost all the way up to the price ceiling. Doing so would not cost him sales since high types would continue to search until eventually buying, however it would make search no longer optimal ex-post. Since this commitment concern is commonly known, an equilibrium in which a price ceiling can deliver the requisite returns to searching in the high demand state is difficult to obtain.

Suppose then that a manufacturer is unable to induce an equilibrium with search with price ceilings alone. If this is the case, then the comparison of outcomes with price ceilings versus with price recommendations is the same comparison as in the previous section. Namely, the manufacturer is worse off with ceilings. By communicating with consumers, the manufacturer can induce them to search if the demand is low and losing this ability can be costly.

\section{Discussion}

This paper addresses the question of how price recommendations can impact a market for consumer goods. I posit that such communication is an attempt by manufacturers to inform consumers about their returns to searching. When aggregate demand is low, the manufacturer induces more search and in doing so reduces retailer markups and increases sales to consumers with low valuations. When aggregate demand is high, the manufacturer induces less search which allows him to charge a higher wholesale price thereby extracting surplus from consumers with high valuations. I show that when search costs are low and aggregate demand is sufficiently uncertain, the manufacturer is able to credibly communicate with consumers via cheap talk.

This model draws a sharp distinction between price recommendations and resale price maintenance. Recommendations are not just an indirect method to manage double marginalization. Though the effect of recommendations is observationally similar to that of price 
ceilings, the mechanism is quite different - in my model the manufacturer influences outcomes by informing consumers rather than imposing constraints on retailers. And while providing information sometimes leads to reduced double marginalization, at other times it leads retailers to actually set higher prices.

While I introduce uncertainty about aggregate demand in the main model, other forms of aggregate uncertainty could potentially make cheap communication possible. For example, consider uncertainty about the manufacturer's costs. A manufacturer facing high costs would be more interested in extracting surplus from high valuation consumers, while a manufacturer facing low costs would be relatively more interested in increasing total sales. At the same time, consumers should expect higher prices in the high cost state and lower prices in the low cost state. I conjecture that when the two cost states are sufficiently different, the manufacturer can credibly communicate his costs via cheap talk.

In practice there is variation in the way actual prices relate to price recommendations. For instance, books often sell for exactly their jacket price while cars tend to sell for strictly less than MSRP. Even within the car market, how far below MSRP a car sells varies by the popularity of that vehicle, and in fact some cars sell above MSRP. Imposing that recommendations are price ceilings or some other exogenously determined restraints precludes the analysis from explaining such variation. Since in my model a recommendation is just a cheap message, I allow for the consumers' interpretation of this message to vary with market conditions and thus can accommodate the varying relationship between prices and recommendations.

The goal of this paper was to highlight a mechanism by which price recommendations serve a purely informational role and still influence market outcomes. Towards this end, the model I develop is quite stylized and thus has limitations for direct use in assessing policy. Nonetheless, the message that seems to emerge is that ceteris paribus price recommendations help consumers, allowing them to make more informed decisions and saving search costs. Hence, an antitrust policy discussion of the merits of price recommendations should keep these informational benefits in mind.

\section{References}

Benabou, R., and R. Gertner (1993): "Search with Learning from Prices: Does Increased Inflationary Uncertainty Lead to Higher Markups," The Review of Economic Studies, 60(1), pp. 69-93.

Berry, S., J. Levinsohn, And A. Pakes (1995): "Automobile Prices in Market Equilibrium," Econometrica, 63(4), pp. 841-890.

Buhler, S., And D. L. Gartner (2009): "Making Sense of Non-Binding Retail-Price Recommendations," Working Papers 0902, University of Zurich, Socioeconomic Institute. 
Crawford, V. P., and J. Sobel (1982): "Strategic Information Transmission," Econometrica, 50(6), pp. 1431-1451.

Diamond, P. A. (1971): "A model of price adjustment," Journal of Economic Theory, $3(2), 156-168$.

Faber, R. P., and M. C. Janssen (2008): "On the Effects of Suggested Prices in Gasoline Markets," Tinbergen Institute Discussion Papers 08-116/1, Tinbergen Institute.

Gill, D., And J. E. Thanassoulis (2010): "The Optimal Marketing Mix of Posted Prices, Discounts and Bargaining," Economics Series Working Papers 479, University of Oxford, Department of Economics.

Horowitz, J. L. (1992): "The Role of the List Price in Housing Markets: Theory and an Econometric Model," Journal of Applied Econometrics, 7(2), pp. 115-129.

Mathewson, G. F., and R. Winter (1984): "An Economic Theory of Vertical Restraints," The RAND Journal of Economics, 15(1), pp. 27-38.

MCCALL, J. J. (1970): "Economics of Information and Job Search," The Quarterly Journal of Economics, 84(1), pp. 113-126.

Puppe, C., and S. Rosenkranz (2006): "Why Suggest Non-Binding Retail Prices?," Working Papers 06-10, Utrecht School of Economics.

Reinganum, J. F. (1979): "A Simple Model of Equilibrium Price Dispersion," The Journal of Political Economy, 87(4), pp. 851-858.

Rothschild, M. (1974): "Searching for the Lowest Price When the Distribution of Prices Is Unknown," The Journal of Political Economy, 82(4), pp. 689-711.

YANG, H., AND L. YE (2008): "Search with learning: understanding asymmetric price adjustments," RAND Journal of Economics, 39(2), 547-564.

\section{Appendix A: Proof of Existence of the Downstream Equilibrium Under Full Information}

I show that a downstream equilibrium that is characterized in Proposition 1 must exist by arguing that equations (8) and (3) are continuous and that they must intersect.

Recall equation (3) which describes the high valuation consumer's threshold:

$$
1-\bar{p}=\max \{0, F(\bar{c})(1-v)+(1-F(\bar{c}))(1-\bar{p})-s\}
$$


and let $\bar{p}^{(3)}(\bar{c})$ be the implicit function implied by this equation. By inspection this function is continuous. First note that $\bar{p}^{(3)}(\bar{c})>v$ for all $\bar{c}$. This can be seen by contradiction. Rewrite equation (3) as

$$
1-\bar{p}=\max \{0,1-\bar{p}+F(\bar{c})(\bar{p}-v)-s\}
$$

If $\bar{p}<v$ then the left hand side must be larger than the right hand side, hence a contradiction. Next note that because of the max operator, $\bar{p}^{(3)}(\bar{c}) \leq 1$ for all $\bar{c}$.

Now recall equation $(8)$

$$
\bar{c}=v-w-\frac{\varphi}{1-\varphi} \frac{\bar{p}-v}{1-\alpha(1-F(\bar{p}-w))}
$$

Recall also that $\bar{p}<1$ implies $\alpha=1$, else if $\bar{p}=1$ any $\alpha \in[0,1]$ can be used to support an equilibrium. In this sense, $\alpha$ helps the existence argument in that for $\bar{p}=1$, there are many values of $\bar{c}$ that can satisfy equation (8) given a choice of $\alpha$.

Let equation (8) implicitly define the function $\bar{p}^{(8)}(\bar{c})$. Continuity once again is obvious here. First note that $\bar{p}^{(8)}(v-w)=v$. Also, note that there exists a $\bar{c}$ low enough (and possibly negative) so that $\bar{p}^{(8)}(\bar{c})=1$.

Hence, $\bar{p}^{(8)}(v-w)<\bar{p}^{(3)}(v-w)$ and $\bar{p}^{(8)}(\bar{c}) \geq \bar{p}^{(3)}(\bar{c})$ for some small enough $\bar{c}$. Given that $\bar{p}^{(8)}(\bar{c})$ and $\bar{p}^{(3)}(\bar{c})$ are continuous functions, they must then intersect.

\section{Appendix B: Proof of the Characterization of the Full Information Equilibrium}

This section provides a proof to Proposition 2, restated here.

Proposition 2 The full information equilibrium is characterized by Proposition 1 and wholesale price $w=\arg \max w \cdot Q(w)$, as given by equation (9). Furthermore, when aggregate demand $\varphi$ and search cost $s$ are sufficiently small, low types are served in equilibrium and high types search until they purchase. When $\varphi$ is sufficiently large no search is induced and low types are excluded.

Proof The proof proceeds through a series of claims.

Lemma 8 When $\varphi$ is small enough, the optimal wholesale price chosen by the manufacturer induces sales to low types.

Proof of Lemma I first show that when the proportion of high valuation consumers $\varphi$ is small enough it is feasible for the manufacturer to induce sales to low types. I then show that it is optimal for him to do so. 
By equation (8)

$$
\begin{aligned}
\bar{c} & =v-w-\frac{\varphi}{1-\varphi} \frac{\bar{p}-v}{1-\alpha(1-F(\bar{p}-w))} \\
& \geq v-w-\frac{\varphi}{1-\varphi} \frac{1-v}{F(v-w)}
\end{aligned}
$$

By inspection, the above expression shows that when $\varphi$ is sufficiently small $\bar{c}(w=0)>0$. In fact, for sufficiently small $\varphi$ there will be a range of wholesale prices that will induce search to low types. Equation (9) then shows that that as $\varphi$ is decreased, the quantity sold by setting a wholesale price that serves only high types goes to zero while the quantity that can be sold with a wholesale price that includes low types is bounded strictly above zero. Hence, it is also optimal for the manufacturer to choose a wholesale price that serves low types.

In fact, I prove a stronger statement about the low state. Specifically, if both $\varphi$ and search cost $s$ are sufficiently small, the manufacturer will optimally induce a downstream equilibrium in which $\alpha=1$.

Lemma 9 When $\varphi$ and search cost s are small enough, high type consumers search in equilibrium with probability $\alpha=1$.

Proof of Lemma Fix a high type consumer's strategy $\bar{p}<1$ and $\alpha=1$. By Lemma 8 there exists a $\varphi$ low enough so that the manufacturer chooses a $w$ to induce sales to low types, and let $\bar{c}$ be the ensuing retailer threshold induced by $w$. In order for this to be an equilibrium, it must be that $\bar{p}<1$ is a best response to the induced price distribution. By inspection of equation (3), for any $\bar{c}$ and $\bar{p}>v$, there exists an $s$ small enough to make the equation hold. Hence $\bar{p}<1$ can be supported in equilibrium and as a result $\alpha=1$ is supported.

I have shown that when $\varphi$ is small, the manufacturer sets an equilibrium wholesale price that induces sales to low types. Furthermore, when the search cost $s$ is small, consumers will search in equilibrium. Next I argue that when $\varphi$ is high enough the manufacturer will set a wholesale price that excludes low types.

Lemma 10 When $\varphi$ is large enough, for any search threshold $\bar{p}>v$ the manufacturer charges a wholesale price $w$ that excludes low types.

Proof of Lemma By equation (1)

$$
\bar{c}=v-w-\frac{\varphi}{1-\varphi}(\bar{p}-v)(1+\kappa) \leq v-\frac{\varphi}{1-\varphi} \cdot s
$$

The second inequality follows from the fact that $\bar{p}-v \geq s$ and $1+\kappa \geq 1$. The above expression is negative for $\varphi$ large enough, hence the manufacturer will not have the option of inducing sales to low types.

Lastly, if there is an equilibrium in which the manufacturer only serves high types, it must 
be that there is no search and $\alpha=0$. The reason is that if only high types are included, and high types follow a threshold strategy, then only a price of 1 can be supported downstream. If the only price charged is 1 then search is never worthwhile. Along with Lemmas 8, 9, and 10 the proves the Proposition.

\section{Appendix C: Proof of Arbitrarily Low Threshold $\bar{p}$ in the Full Information Equilibrium}

This section proves that for any small $\bar{p}>0$, there exist small enough $\varphi, s$, and $v$ so that $\bar{p}$ is supported in the full information equilibrium. I will show this by first noting that a manufacturer's profits in any equilibrium are bounded away from zero. Then, I will show that as $s$ and $\varphi$ are reduced toward zero, either $\bar{p}$ approaches $v$ or the manufacturer's profit approaches zero, which would contradict the first statement. Lastly, since $\bar{p}$ can be made arbitrarily close to $v$, when $v$ is chosen to be small, $\bar{p}$ will be small as well.

First, recall that by Lemma 9, the manufacturer chooses to set a wholesale price $w$ to induce sales to low types, i.e. he induces $\bar{c}>0$. It will be useful for this argument to show that as $\varphi \rightarrow 0$, the manufacturer's profit is uniformly bounded strictly above 0 .

Claim 11 For any $\delta>0$, there exists a low enough $\hat{\varphi}$ so that for any $\varphi<\hat{\varphi}$, the manufacturer's equilibrium profit exceeds $v / 2 \cdot F(v / 2)-\delta$.

Proof of Claim: The manufacturer's equilibrium profit, given $w$ is the optimally charged wholesale price, is given by

$$
\begin{aligned}
\Pi(w, \varphi) & =w((1-\varphi) F(\bar{c}(w, \varphi))+\varphi \cdot \mathbb{I}(w \leq \bar{p})) \\
& \geq w\left((1-\varphi) F\left(v-w-\frac{\varphi}{1-\varphi} \frac{\bar{p}-v}{F(\bar{p}-w)}\right)\right) \quad \text { (by equation (8)) } \\
& =w(F(v-w)-\underbrace{\left(F\left(v-w-\frac{\varphi}{1-\varphi} \frac{\bar{p}-v}{F(\bar{p}-w)}\right)-F(v-w)\right)}_{A}-\underbrace{\varphi F\left(v-w-\frac{\varphi}{1-\varphi} \frac{\bar{p}-v}{F(\bar{p}-w)}\right)}_{B})
\end{aligned}
$$

Consider a manufacturer that charges $w=v / 2$. At this wholesale price, $\bar{p}-w \geq v+s-w \geq$ $v / 2+s>0$, hence both terms $A$ and $B$ go to zero as $\varphi$ goes to zero. For $\varphi$ low enough, $v / 2 \cdot(A+B)<\delta$. Hence, $\Pi(w, \varphi) \geq \Pi(v / 2, \varphi) \geq v / 2 \cdot F(v / 2)-\delta$.

Next, I prove by contradiction that as $s$ and $\varphi$ decrease, $\bar{p}-v$ approaches zero. Suppose toward a contradiction that there exists an $\varepsilon>0$ such that there is some $\hat{s}$ with the property that for any $s<\hat{s}$, in the full information equilibrium $\bar{p}-v>\varepsilon$. By equation (12), this implies that $\frac{s}{F(\bar{c})}>\varepsilon$ for any $s<\hat{s}$. Recall equation (8):

$$
\bar{c}=v-w-\frac{\varphi}{1-\varphi} \frac{\bar{p}-v}{F(\bar{p}-w)}
$$


For small enough $\varphi$ in any equilibrium $w<v$. By the hypothesis above, this implies that $\bar{p}-w \geq \bar{p}-v \geq \varepsilon$ for all $s<\hat{s}$. Then as $s$ and $\varphi$ both shrink toward zero, the right hand side of the equation above must approach $v-w$. At the same time, since by hypothesis $\frac{s}{F(\bar{c})}>\varepsilon$ for all small $s$, it must be that $\bar{c}$ is converging toward zero. Hence, it must be that as $s$ and $\varphi$ shrink toward zero, the equilibrium $w$ approaches $v$. However, this implies that the manufacturer's equilibrium profit approaches zero which contradicts the claim above since the manufacturer's profit has an absolute lower bound strictly above zero.

Hence I have shown that as search cost $s$ and low state demand $\varphi_{L}$ diminish toward zero, the equilibrium search threshold $\bar{p}$ approaches the low types' valuation $v$. Thus, there always exists a full information equilibrium where the search threshold is arbitrarily close to zero given parameters $\varphi, s$, and $v$ are all chosen to be sufficiently small.

\section{Appendix D: Proof of Existence of a No Search Equilib- rium When Recommendations are Banned}

When recommendations are banned, I show that an equilibrium with no search can be supported when initial belief $\lambda_{0}$ is sufficiently high.

Proof In the proposed equilibrium, retailers face the step demand function

$$
q(p)=\left\{\begin{array}{cl}
1 & \text { if } p \in[0, v] \\
1-\varphi & \text { if } p \in(v, 1] \\
0 & \text { if } p \in(1, \infty)
\end{array}\right.
$$

Retailers use threshold strategy $\bar{c}$ given by equation (1)

$$
\bar{c}(w, \varphi)=v-w-\frac{\varphi}{1-\varphi}(1-v)
$$

Given an equilibrium where consumers do not search, the manufacturer solves

$$
\max _{w} w \cdot Q(w, \varphi)=w \cdot((1-\varphi) F(\bar{c}(w, \varphi))+\varphi F(1-w))
$$

in each state $\varphi$, with $\bar{c}(w, \varphi)$ given above and decreasing in $w$. Let $w(\varphi)$ be the solution to the above optimization and note that $0<w(\varphi)<1$.

Claim 12 When $\varphi_{H}$ is large enough, $\bar{c}\left(\varphi_{H}\right) \leq 0$ and when $\varphi_{L}$ is small enough $\bar{c}\left(\varphi_{L}\right)>0$ in equilibrium.

Proof of Claim This does not follow immediately because in equation (1) wholesale prices are endogenous. That $\bar{c}\left(\varphi_{H}\right) \leq 0$ for a large enough $\varphi_{H}$ does follow directly. From the manufacturer's optimization it is clear that when $\varphi_{L}$ is small enough, setting a $w$ that induces $\bar{c}>0$ is optimal and by (1) also feasible for the manufacturer. Hence, when $\varphi_{L}$ is small enough $\bar{c}_{L}>0$. 
On the supply side I have shown that when consumers follow the strategy of no search then only a price of 1 is charged in the high state and prices $v$ and 1 are charged in the low state. Next, I must show that no searching is a best response for consumers. For notational clarity, define

$$
\begin{array}{ll}
w_{L} \equiv w\left(\varphi_{L}\right), & w_{H} \equiv w\left(\varphi_{H}\right) \\
\bar{c}_{L} \equiv \bar{c}\left(w_{L}, \varphi_{L}\right), & \bar{c}_{H} \equiv \bar{c}\left(w_{H}, \varphi_{H}\right)
\end{array}
$$

Low valuation consumers expect no prices strictly below $v$ in either state and will either purchase on their first price draw or exit. High valuation consumers will assign a likelihood to the high state conditional on the price they see according to

$$
\lambda(p)= \begin{cases}0 & \text { if } p=v \\ \lambda_{0} \frac{F\left(1-w_{H}\right)}{F\left(1-w_{L}\right)-F\left(\bar{c}_{L}\right)} & \text { if } p=1 \\ \lambda_{0} \frac{1-F\left(1-w_{H}\right)}{1-F\left(1-w_{L}\right)} & \text { if } p=\infty \\ \lambda_{0} & \text { for all other } p\end{cases}
$$

Likelihoods at equilibrium prices are computed as the product of the prior likelihood $\lambda_{0}$ and the ratio of the probabilities of seeing the price in either state. Prices off the equilibrium path are by assumption ignored by consumers when forming beliefs. Note that likelihood $\lambda$ translates into belief $\mu=\frac{\lambda}{\lambda+1}$.

A high type consumer whose lowest observed price is $p$ and who holds belief $\mu$ has a value function recursively defined by

$$
V(p, \mu)=\max \left\{0,1-p, E\left[V\left(p^{\prime}, \mu^{\prime}\right) \mid p, \mu\right]-s\right\}
$$

Claim 13 There exists a high enough belief $\bar{\mu}$ so that whenever $\mu>\bar{\mu}$, the continuation value to searching $E\left[V\left(p^{\prime}, \mu^{\prime}\right) \mid p, \mu\right]-s<\max \{0,1-p\} \forall p$.

Proof of Claim I provide an upper bound for the continuation value to searching:

$$
E\left[V\left(p^{\prime}, \mu^{\prime}\right) \mid p, \mu\right]-s \leq \mu(\max \{1-p, 0\})+(1-\mu)(1-v)-s
$$

If the state is high, the consumer will not see a price below 1 and the highest payoff she can obtain is to accept $p$ if it is less than 1 else exit. If the state is low, the highest payoff the consumer can get is if she observes and accepts price $v$. For large enough $\mu$, it must then be that $E\left[V\left(p^{\prime}, \mu^{\prime}\right) \mid p, \mu\right]-s<\max \{0,1-p\}$.

To restate the claim, for any price $p$ once consumers are convinced enough the state is high they will not search and either purchase or exit.

Claim 14 There exists a $\bar{\lambda}$ so that for any $\lambda_{0}>\bar{\lambda}, \mu(p)>\bar{\mu} \forall p$.

Proof of Claim The proof follows from equation I have thus shown that for large enough $\lambda_{0}$ no price will induce search and this concludes the proof of the lemma. 